\title{
Correspondence
}

Archives of Disease in Childhood, 1972, 47, 676.

\section{Intramural Jejunal Haematoma Complicating Peroral Mucosal Biopsy}

Sir,

I read with interest the report by Ahmed and Patel in your issue of October 1971 concerning an intramural jejunal haematoma complicating peroral mucosal biopsy. Mullinger et al. reported a similar case in 1971, and another case of apparent duodenal haematoma complicating small intestinal biopsy, which was diagnosed radiologically and managed conservatively in a child with coeliac disease, was reported from this hospital during the same year (Walker-Smith, 1971). This was the only complication encountered from 579 biopsies performed at this hospital since 1 January 1966.

Both of these reports were similar to that of Ahmed and Patel as there was no evidence of a coagulation defect nor evidence of local injury to a blood vessel. While it is possible that a shearing stress with indirect injury to a blood vessel may account for the haematoma, I feel that it is only speculation to suggest that the presence of malrotation may have contributed to the production of the haematoma. Both of the other reported cases occurred in children who did not have malrotation. At present it is not clear why an intramural haematoma complicated biopsy in these 3 children. Incomplete avulsion of the mucosal specimen at first, followed by elevation of part of the mucosa from the submucosa before complete avulsion of the biopsy specimen, could account for this phenomenon.

These experiences reinforce the view that small bowel iv biopsy in children, while an essentially safe procedure, $A$ is associated with some morbidity, albeit infrequently, and should be performed circumspectly. Children oे should have their small intestinal mucosa biopsied only 은 when direct benefit to the child from this investigation can be expected either diagnostically, prognostically, or therapeutically.

\author{
J. A. WALKER-SMITH \\ Department of Gastroenterology, \\ Royal Alexandra Hospital for Children, \\ Camperdown 2050, \\ Sydney, N.S.W., Australia.
}

\section{REFERENCES}

Ahmed, S., and Patel, R. G. (1971). Intramural jejunal haematoma after peroral mucosal biopsy in a child with intestinal malrotation. Archives of Disease in Childhood, 46, 723.

Mullinger, M., Wood, B. J., Kliman, M. R., and Robinson, G. C. (1971). Intramural haematoma of the duodenum: an unusual complication of small bowel biopsy. Fournal of Pediatrics, 78, 323.

Walker-Smith, J. A. (1971). Diagnosis and treatment of coeliac disease in childhood. Medical fournal of Australia, 1, 931. 